\title{
Influence of Experiential Teaching and Itinerary Assessment on the Improvement of Key Competencies of Students
}

\author{
https://doi.org/10.3991/ijet.v17i02.29007 \\ Boru Lu, Fan Zheng( $(\varpi)$ \\ School of Accounting, Yanching Institute of Technology, Sanhe, China \\ zhengfan@yit.edu.cn
}

\begin{abstract}
The thinking and inquiry abilities of students can be improved effectively only through practical exploration and personal experience. To improve the key competences and promote individual development of students, it is important to arrange experiential teaching pertinently, and handle the learning problems timely, referring to the results of itinerary assessment. This paper explores the influence of experiential teaching and itinerary assessment on the improvement of key competencies of students. Firstly, a regression model was established to evaluate the improvement of students' key competencies, based on stepwise regression. Next, the Iterative Dichotomiser 3 (ID3) model was adopted to classify the tuple of each test sample or research object. Finally, the association rule mining technique was applied to the benchmark evaluation of the improvement of students' key competencies, and the three benchmark evaluation models were synthetized into an integrated model. The effectiveness of the proposed model was demonstrated through experiments.
\end{abstract}

Keywords—experiential teaching, itinerary assessment, improvement of key competencies

\section{Introduction}

The inner competencies of students, the subject in the process of education, are attracting more and more attention [1-4]. The spoon-fed theoretical knowledge cannot essentially improve the students' competencies. The thinking and inquiry abilities of students can be improved effectively only through practical exploration and personal experience [5-10]. Information-based teaching synthesizes various learning methods. The learning effect of information-based teaching cannot be purely measured by test scores. The dynamic learning state can be captured in real time by analyzing the learning behaviors and competence improvement in each phase of learning throughout the teaching process [11-18]. To improve the key competences and promote individual development of students, it is important to arrange experiential teaching pertinently, and handle the learning problems timely, referring to the results of itinerary assessment. 
Guerra and Shealy [19] proposed a new method of evaluating students, providing them with an opportunity of experiential learning. Following Kolb's learning cycle, seniors were divided into two-person groups were asked to complete two unique experimental projects within 12 weeks in three months. The students spoke highly of the course experience, and recognized that the projects increase their employment opportunities after graduation in the directly related fields. Through user-centered design, Marriott and Lau [20] taught the active learning methods of sustainable infrastructure to civil engineering students. The students were required to emulate the role of community members in design charrette, interview the stakeholders, and write down their reflections. The purpose is to measure the influence of two active learning methods on student design. On itinerary assessment, Jiang and Jiang [21] reported the results of a case study on freshmen majoring in accounting. During the study, a series of online summative evaluations was introduced to the evaluation system of one of the modules, and the evidence was presented to how technology successfully serves the evaluation purpose. The results show that assessment is critical to the teaching process. In the actual process of learning assessment, the evaluation index system is often chaotic, under the effect of non-process data. The chaotic system undermines the credibility of the final outcome of assessment. Xia et al. [22] designed an assessment method for online learning process in the context of education big data, and set up an acquisition network for online learning process. The learning process data acquired by the network were classified by technical direction, and teaching design direction. On this basis, an evaluation index system was constructed, and the indices on the same level were assigned the same weight. According to the weights, the process assessment strategy was developed. With the continuous improvement of large-scale online teaching platforms, the blended learning model becomes an important trend. Against this backdrop, Maizeli et al. [23] built a whole-process teaching quality assessment system under blended learning, and further analyzed the application of specific courses through online structuring and platform display.

The existing studies on experiential teaching and itinerary assessment face several problems: the absence of unified evaluation criteria, the insufficient information level of evaluation records, the complex evaluation measures, and the lack of quantitative analysis. Therefore, it is urgent to establish a scientific evaluation system, and build an accurate assessment model. This paper explores the influence of experiential teaching and itinerary assessment on the improvement of key competencies of students. The main contents of the research are as follows: (1) setting up a regression model based on stepwise regression, and using the model to process the factors that affect the dependent variable, students' key competencies; (2) introducing the Iterative Dichotomiser 3 (ID3) model to evaluate the improvement of students' key competencies, and to classify the tuple of each test sample or research object; (3) applying the association rule mining technique to the benchmark evaluation of the improvement of students' key competencies; (4) synthetizing the three benchmark evaluation models into an integrated model, which processes the benchmark evaluation results by voting. The effectiveness of the proposed model was demonstrated through experiments. 


\section{Regression model}

In conventional statistical problems, the totality of the research objects is usually called the population, the research objects making up the population are called individuals, and the total number of objects is called volume. Take the statistical task of improvement of students' key competencies under experiential teaching and itinerary assessment for example. The population is the state of experiential teaching and itinerary assessment of all students; the individuals are the state of each evaluation factor of each student against each index.

To obtain the features of the improvement of students' key competencies, it is necessary to sample a certain proportion of the target students. To examine the improvement of students' key competencies under experiential teaching and itinerary assessment, sufficient samples should be randomly collected from the students receiving experiential teaching, those receiving itinerary assessment, and those receiving both experiential teaching and itinerary assessment.

To evaluate the improvement of students' key competencies, an evaluation model needs to be established in two steps: building a multiple regression equation; performing benchmark evaluation based on the established model. In this paper, a regression model is constructed for the improvement of students' key competencies based on stepwise regression, and used to process the factors that affect the dependent variable, students' key competencies. Let $\mathrm{n}$ be the number of influencing factors; $\gamma_{i}$ be the regression coefficient; $\varepsilon$ be a random error. Then, the dependent variable $b$ and $\mathrm{n}$ independent variables $a_{1}, a_{2}, \ldots, a_{n}$ can form a linear regression model:

$$
b=\gamma_{0}+\gamma_{1} a_{1}+\gamma_{2} a_{2}+\ldots+\gamma_{n} a_{n}+\rho
$$

The regression model (1) can be referred to as the full model. Then, $t$ factors $a_{1 t}$, $a_{2 t}, \ldots, a_{t t}$ were selected from the $\mathrm{n}$ factors, and combined into another regression model:

$$
b=\gamma_{0 t}+\gamma_{1 t} a_{1 t}+\gamma_{2 t} a_{2 t}+\ldots+\gamma_{t} a_{t t}+\rho_{t}
$$

Model (2) can be referred to as the selected model. The partial F-test is a necessary step to remove or add a factor to the regression equation.

Let $\left(a_{11}, a_{12}, a_{13}, \ldots, a_{1 m}, b_{1}\right),\left(a_{21}, a_{22}, a_{23}, \ldots, a_{2 m}, b_{2}\right), \ldots,\left(a_{n 1}, a_{n 2}, a_{n 3}, \ldots, a_{n m}, b_{n}\right)$ be the collected data samples about experiential teaching and itinerary assessment, with $b_{i}(i \leq k \leq n)$ being the quantified value of the dependent variable. Based on these $\mathrm{n}$ samples, a regression equation can be established as:

$$
b=\gamma_{0}+\gamma_{1} a_{1}+\gamma_{2} a_{2}+\ldots+\gamma_{n} a_{n}
$$

The corresponding statistics can be expressed as:

$$
\bar{b}=\frac{\sum_{i=1}^{i=n} b_{i}}{n}
$$




$$
\hat{b}_{i}=\gamma_{0}+\gamma_{1} a_{i 1}+\gamma_{2} a_{i 2}+\ldots+\gamma_{n} a_{i n}
$$

The regression sum of squares can be calculated by:

$$
H P H=\sum_{i=1}^{i=n}\left(\hat{b}_{i}-\bar{b}\right)^{2}
$$

The error sum of squares can be calculated by:

$$
H P G=\sum_{i=1}^{i=n}\left(b_{i}-\hat{b}_{i}\right)^{2}
$$

The total sum of squares can be calculated by:

$$
H P Z=\sum_{i=1}^{i=n}\left(b_{i}-\bar{b}\right)^{2}=\sum_{i=1}^{i=n}\left(\hat{b}_{i}-\bar{b}\right)^{2}+\sum_{i=1}^{i=n}\left(b_{i}-\hat{b}_{i}\right)^{2}
$$

Hence, the total sum of squares is the superposition of the regression sum of squares and the error sum of squares: $H P Z=H P H+H P G$.

The significance of factor $a_{i}(1 \leq i \leq n)$ is discussed below. After removing $a_{i}$, a regression was carried out with $b$ and the remaining $n-1$ factors. Let $H P G_{(i)}$ and $H P H_{(i)}$ be the calculated residual sum of squares, and regression sum of squares, respectively. Then, the contribution of $a_{i}$ to the regression, i.e., the sum of the partial regression equation of $a_{i}$ can be characterized by $\triangle H P H_{(i)}=H P H-H P H_{(i)}$. Based on the sum of the partial regression equation, the partial F-statistic can be calculated by:

$$
P F S_{i}=\frac{\Delta H P H_{(i)} / 1}{H P G /(n-m-1)}
$$

If the hypothesis of the regression model $S U_{0 i}: \gamma_{i}=0$ holds, the partial F-statistic in formula (9) obeys the F-distribution with the degree of freedom of $(1, n-m-1)$.

\section{Decision Tree (DT) classification}

The most influential DT classifier is ID3 algorithm. In this paper, the ID3 algorithm is adopted to construct and train a classifier on the collected data samples on experiential teaching and itinerary assessment. In this way, the ideal classification rules were deduced from a set of unordered and irregular data samples, and expressed as a DT.

The ID3 evaluation of the improvement of students' key competencies is realized in two steps. The first step is to describe the given training set, and construct a DT model by analyzing the tuples of the experimental teaching and itinerary assessment sample library, which are described by the quantified values of evaluation indices. For each factor, every tuple corresponds to a preset class, and each class has a unique 
label about tuple attributes. In other words, the model learning is carried out under the premise that the class of each training sample is already known. Each sample could belong to one of the following three classes: the class of experiential teaching, the class of itinerary assessment, and the class of both experiential teaching and itinerary assessment. The second step is to predict the improvement of students' key competencies with the established model, and classify the tuple of each test sample or research object.

Different from the other DT models, the ID3 always determines the quantified value of the current node against indies as the value with the largest entropy compression. Let $\mathrm{R}$ be the set of $\mathrm{r}$ evaluation samples; $\mathrm{n}$ be the different values of tuple attributes. Then, it is necessary to define $D=(i=1,2, \ldots, n)$ in n different classes, with $D_{i}$ containing $r_{i}$ samples. The expectation needed for sample classification can be calculated by:

$$
E X\left(r_{1}, r_{2}, \ldots, r_{n}\right)=-\sum_{i=1}^{n} F Q_{i} \log _{2}\left(F Q_{i}\right)
$$

The probability $F Q_{i}$ for any sample to belong to $D_{i}$ can be estimated from $r_{i} / r$.

Suppose a sample has $\tau$ different quantified values $X=\left\{x_{1}, x_{2}, \ldots x_{\tau}\right\}$ against indices. Then, R can be divided into $\tau$ subsets $\left\{R_{1}, R_{2}, \ldots R_{\tau}\right\}$ by X, where $R_{j}$ contains the samples in $\mathrm{R}$ that have the value $x_{j}$ in $\mathrm{X}$. Taking $\mathrm{X}$ as the best split attribute of the DT, the branch growing from the nodes in $\mathrm{R}$ correspond the $\tau$ subsets.

Let $r_{i j}$ be the number of subset $R_{j}$ samples belonging to tuple attribute class $D_{i}$. Then, the entropy of a subset divided by $\mathrm{X}$ can be calculated by:

$$
\Psi(X)=-\sum_{j=1}^{\tau} \frac{r_{1 j}+r_{2 j}+\ldots+r_{n j}}{r} E X\left(r_{1 j}, r_{2 j}, \ldots, r_{n j}\right)
$$

The higher the purity of the subset class, the smaller the entropy. Let $F Q_{i j}$ be the probability for an $R_{j}$ sample to belong to tuple attribute class $D_{i}$. Based on the expectation formula (10), the expectation of a given sample subset can be calculated by:

$$
E X\left(r_{1}, r_{2}, \ldots, r_{n}\right)=-\sum_{i=1}^{n} F Q_{i j} \log _{2}\left(F Q_{i j}\right)
$$

The $F Q_{i j}$ can be calculated by:

$$
F Q_{i j}=\frac{r_{i j}}{\left|r_{j}\right|}
$$

The information gain can be derived from the expectation and entropy obtained above. The information gain of a branch in $\mathrm{X}$ can be calculated by:

$$
G I(X)=E X\left(r_{1}, r_{2}, \ldots, r_{m}\right)-\Psi(X)
$$




\section{$4 \quad$ Association rule mining}

Under the conditions of experiential teaching and itinerary assessment, the improvement of students' key competencies can be evaluated by comparing the students' learning effect, learning ability, and learning quality of experiential teaching in different learning phases against unified criteria.

Firstly, it is necessary to collect the student entities and the relevant sample data, including the evaluated values of experiential teaching, the quantified values of the learning effect in each phase, as well as tuple attributes like the duration of experiential teaching, and number of learning phases under itinerary assessment. The law or rules detected from these data can be applied to evaluate the degree of improvement of students' key competencies. The sample set used to generate evaluation law or criteria is referred to as the training set. The only goal of evaluation is the degree of improvement of students' key competencies.

Suppose the training set contains $\mathrm{N}$ indices $a_{1}, a_{2}, \ldots, a_{N}$ of the two evaluation objects, and the evaluation goal is b. Let $m_{1}, m_{2}, \ldots, m_{n}$ be the number of levels of each index; $a_{1}=\left\{a_{11}, a_{12}, \ldots, a_{1 m 1}\right\}, a_{2}=\left\{a_{21}, a_{22}, \ldots, a_{2 m 2}\right\}, \ldots, a_{n}=\left\{a_{n 1}, a_{n 2}, \ldots, a_{n m n}\right\}$ be the quantified values of each evaluation level; $b=\left\{b_{1}, b_{2}, \ldots, b_{m}\right\}$ be the m levels of the evaluation goal; $E=\left\{s_{1}, s_{2}, \ldots, s_{l}\right\} \quad$ be the training set of $f$ samples, with $s_{i}(i=1,2, \ldots, f)=\left\{x_{i 1}, x_{i 2}, \ldots, x_{i(n+1)} \mid x_{i j} \in a_{j}\right.$, and $\left.x_{i(n+1)} \in b, j=1,2, \ldots, n\right\} . s_{i}(i=1,2, \ldots, f)$ can be called a record of experiential teaching and itinerary assessment.

The project set $P C \in\left\{a_{1}, a_{2}, \ldots, a_{3}, b\right\}$ for the evaluation of the improvement of students' key competencies is defined as the collection of all index values and goal values:

$$
P C=\left\{a_{11}, a_{12}, \ldots, a_{1 m_{1}}, a_{21}, a_{22}, \ldots, a_{2 n_{2}}, a_{n 1}, a_{n 2}, \ldots, a_{n m_{n}}, b_{1}, b_{2}, \ldots, b_{m}\right\}
$$

Association rule mining is often utilized to discover knowledge rules from a fixed database. If multiple data values recur frequently in the dataset, there must be an association between these data items. The association rule can be established through association rule mining. When it comes to the benchmark evaluation of the improvement of students' key competencies, the association rule mining aims to generate association rules for different student samples, and apply these rules to student entities waiting to be tested or evaluated.

Traditionally, association rule mining targets transaction databases. For the benchmark evaluation of the improvement of students' key competencies, the association rule mining faces the training set defined in the preceding section.

In the training set $E=\left\{s_{1}, s_{2}, \ldots, s_{f}\right\}$, each record $s_{i}(i=1,2, \ldots, f)$ corresponds to a subset of the project set PC. Assuming that $P C_{1} \in P C$, the support of project subset $P C_{1}$ on training set $\mathrm{E}$ can be defined as the proportion of $P C_{1}$-containing records in $\mathrm{E}$ :

$$
\operatorname{SUP}\left(P C_{1}\right)=\frac{\left\|\left\{s \in E \mid P C_{1} \in s\right\}\right\|}{\|E\|}
$$


For $P C$ and $E$, all the project subsets meeting the preset minimum support, i.e., the non-empty subsets of PC with a support greater than or equal to the minimum support, are defined as the frequent itemsets.

Based on PC and E, association rules marked by record label $E X_{1} \rightarrow E X_{2}$ can be determined against the thresholds of credibility, trust, or significance. Among them, credibility stands for records labeled $E X_{1}$ and $E X_{2}$ as a proportion of the records labeled $E X_{1}$ :

$$
\operatorname{CON}\left(E X_{1} \rightarrow E X_{2}\right)=\operatorname{SUP}\left(E X_{1} \cup E X_{2}\right) / \operatorname{SUP}\left(E X_{1}\right)
$$

where, $E X_{1}, E X_{2} \subseteq E X ; E X_{1} \cap E X_{2}=\phi$.

The strong association rule is defined as an association rule with $E$ satisfying minimum SUP and minimum CON on EX.

Suppose the data are available on 10 student entities. Then, the evaluation indies for experiential teaching and itinerary assessment can be enumerated as follows:

For experimental teaching:

1. Primary index

$E T=\left\{E T_{1}, E T_{2}\right\}=\{$ experience of experiential learning, overall performance of students' key competencies $\}$

\section{Secondary indices}

$E T_{1}=\left\{E T_{11}, E T_{12}, E T_{13}\right\}=\{$ participation attitude, experience process, experience situation $\}$

$E T_{2}=\left\{E T_{21}, E T_{22}, E T_{23}\right\}=\{$ theoretical concept, logical thinking, inquiry ability $\}$

\section{Tertiary indices}

$E T_{11}=\left\{E T_{111}, E T_{112}\right\}=\{$ learning interest, experience perception $\}$

$E T_{12}=\left\{E T_{121}, E T_{122}, E T_{123}\right\}=\{$ pre-class, in-class, post-class $\}$

$E T_{13}=\left\{E T_{131}, E T_{132}\right\}=\{$ teaching environment, teaching situation design $\}$

$E T_{21}=\left\{E T_{211}, E T_{212}\right\}=\{$ concept, law, practice $\}$

$E T_{22}=\left\{E T_{221}, E T_{222}\right\}=\{$ derivation ability, problem finding ability, problem solving ability

$E T_{23}=\left\{E T_{231}, E T_{232}\right\}=\{$ knowledge expansion ability, scientific research and innovation ability

In actual classroom, the learning quality and learning effect could be influenced by learning interest, learning motivation, learning environment, and teaching contents. The actual learning state of students is generally analyzed from two aspects: emotional attitude, and learning contents. Therefore, this paper decides to evaluate experiential teaching from three dimensions, namely, theoretical concept, logical thinking, and inquiry ability, laying the basis for designing the contents and scenarios of a feasible experiential teaching model.

Figure 1 shows the structure of the itinerary assessment model for informationbased teaching. The itinerary assessment lasts from the very beginning to the end of 
experiential teaching activities. Referring to the evaluation goal, the different learning phases, namely, pre-class, in-class, and post-class, were evaluated differently against the following indices:

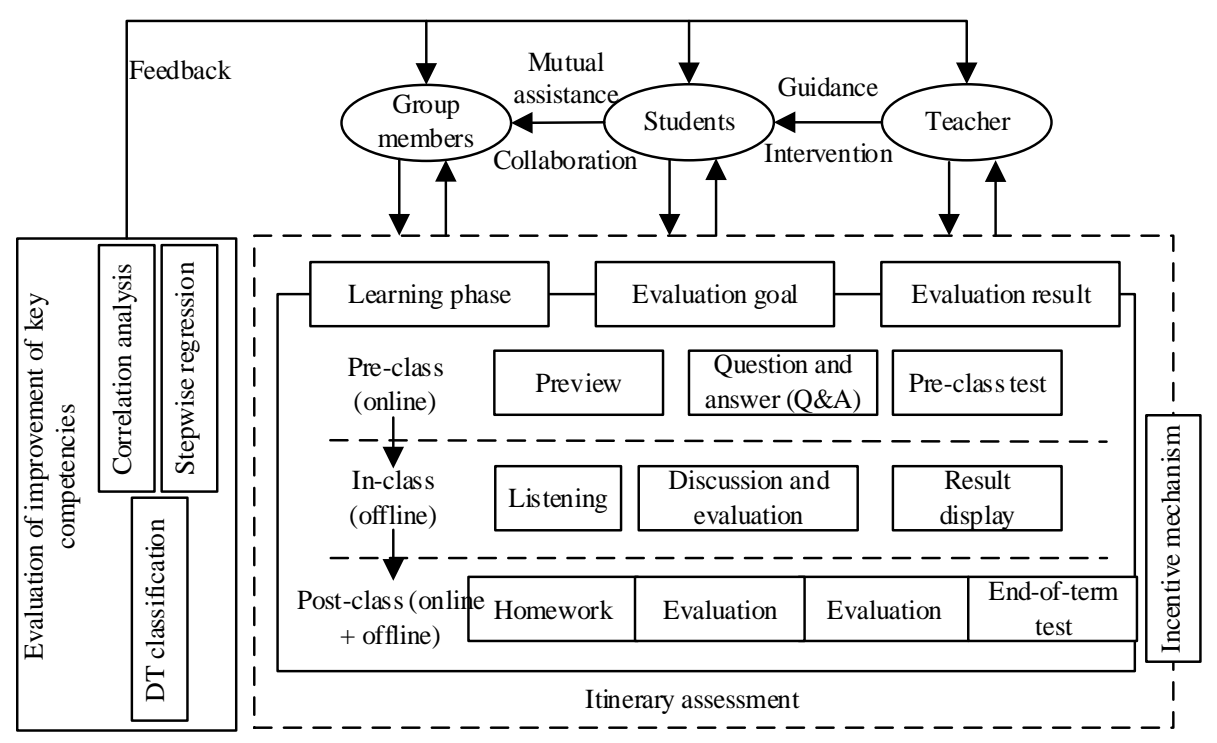

Fig. 1. Itinerary assessment model for information-based teaching

\section{Primary index}

$I A=\left\{I A_{1}, I A_{2}, I A_{3}\right\}=\{$ pre-class evaluation, in-class evaluation, post-class evaluation\}

2. Secondary indices

$I A_{1}=\left\{I A_{11}, I A_{12}\right\}=\{$ evaluation goal, evaluation process $\}$

$I A_{2}=\left\{I A_{21}, I A_{22}, I A_{23}\right\}=\{$ evaluation goal, evaluation process, evaluation effect $\}$

$I A_{3}=\left\{I A_{31}, I A_{32}, I A_{33}\right\}=\{$ evaluation goal, evaluation process, evaluation effect $\}$

3. Tertiary indices

$I A_{11}=\left\{I A_{111}, I A_{112}\right\}=\{$ video viewing duration, resource views $\}$

$I A_{12}=\left\{I A_{121}, I A_{122}\right\}=\{$ number of questions, number of pre-class tests $\}$

$I A_{21}=\left\{I A_{211}\right\}=\{$ attendance $\}$

$I A_{22}=\left\{I A_{221}, I A_{222}, I A_{223}, I A_{224}\right\}=\{$ topic discussion, teacher-student interaction, student-student interaction, question answering $\}$

$I A_{23}=\left\{I A_{231}, I A_{232}\right\}=\{$ classroom summary, result display $\}$

$I A_{31}=\left\{I A_{311}, I A_{312}\right\}=\{$ number of homework submissions, number of homework mutual evaluations $\}$

$I A_{32}=\left\{I A_{321}, I A_{322}, I A_{323}\right\}=\{$ theoretical learning (self-evaluation, mutual evaluation, teacher evaluation), practical skills (self-evaluation, mutual evaluation, teacher evalu- 
ation), end-of-term evaluation (self-evaluation, mutual evaluation, teacher evaluation) $\}$

$I A_{33}=\left\{I A_{331}, I A_{332}\right\}=\{$ online learning participation, end-of-term test score $\}$

The possible values of the tertiary indices of the two evaluation objects are $E T_{11}=\left\{E T_{111}, E T_{112}\right\}, E T_{12}=\left\{E T_{121}, E T_{122}, E T_{123}\right\}, E T_{13}=\left\{E T_{131}, E T_{132}\right\}, E T_{21}=\left\{E T_{211}\right.$, $\left.E T_{212}\right\}, E T_{22}=\left\{E T_{221}, E T_{222}\right\}, E T_{23}=\left\{E T_{231}, E T_{232}\right\}, I A_{11}=\left\{I A_{111}, I A_{112}\right\}, I A_{12}=\left\{I A_{121}\right.$, $\left.I A_{122}\right\}, I A_{21}=\left\{I A_{211}\right\}, I A_{22}=\left\{I A_{221}, I A_{222}, I A_{223}, I A_{224}\right\}, I A_{23}=\left\{I A_{231}, I A_{232}\right\}, I A_{31}=\left\{I A_{311}\right.$, $\left.I A_{312}\right\}, I A_{32}=\left\{I A_{321}, I A_{322}, I A_{323}\right\}$, and $I A_{33}=\left\{I A_{331}, I A_{332}\right\}$. For simplicity, the training set composed of the above indices is denoted as $E$.

According to the previous definitions, the project set of training set $\mathrm{E}$ can be described as $P C=\left\{E T_{111}, E T_{112}, E T_{121}, E T_{122}, E T_{123}, E T_{131}, E T_{132}, E T_{211}, E T_{212}, E T_{221}\right.$, $E T_{222}, E T_{231}, E T_{232}, I A_{111}, I A_{112}, I A_{121}, I A_{122}, I A_{211}, I A_{221}, I A_{222}, I A_{223}, I A_{224}, I A_{231}, I A_{232}$, $\left.I A_{311}, I A_{312}, I A_{321}, I A_{322}, I A_{323}, I A_{331}, I A_{332}\right\}$. The project subset $P C_{1}=\left\{E T_{1}, E T_{2}\right\}$ is a subset of $\mathrm{PC}$, which contains all the records of experiential teaching. The support of $P C_{1}$ on $E$ can be expressed as:

$$
\operatorname{SUP}\left(P C_{1}\right)=\frac{\left\|\left\{s \in E \mid P C_{1} \in s\right\}\right\|}{\|E\|}=\frac{3.5}{10}=0.35
$$

The project subset $P C_{2}=\left\{I A_{1}, I A_{2}, I A_{3}\right\}$ is the other subset of PC, which contains all the records of itinerary assessment. The support of $P C_{2}$ on $E$ can be expressed as:

$$
\operatorname{SUP}\left(P C_{2}\right)=\frac{\left\|\left\{s \in E \mid P C_{2} \in s\right\}\right\|}{\|E\|}=\frac{2.2}{10}=0.22
$$

For $P C_{1}=\left\{E T_{1}, E T_{2}\right\}$ and $P C_{2}=\left\{I A_{1}, I A_{2}, I A_{3}\right\}$, it can be calculated that $\operatorname{SUP}\left(P C_{1}\right)=0.35$, and $\operatorname{SUP}\left(P C_{2}\right)=0.22$. Thus, the credibility of rule $P C_{1} \rightarrow P C_{2}$ is the support of project set $\left\{P C_{1} \cup P C_{2}\right\}$ divided by the support of PC:

$$
\operatorname{CON}\left(P C_{1} \rightarrow P C_{2}\right)=\operatorname{SUP}\left(P C_{1} \cup P C_{2}\right) / S U P\left(P C_{1}\right)=0.35 / 0.22=1.59
$$

This paper proposes an integrated model based on three benchmark evaluation models, including stepwise regression, DT algorithm, and association rule mining. The model processes the benchmark evaluation results through voting to yield the final evaluation result (Figure 2). The voting operation can achieve a good and stable classification effect on large sample sets. As a result, the integration model is superior to the three benchmark evaluation models. 


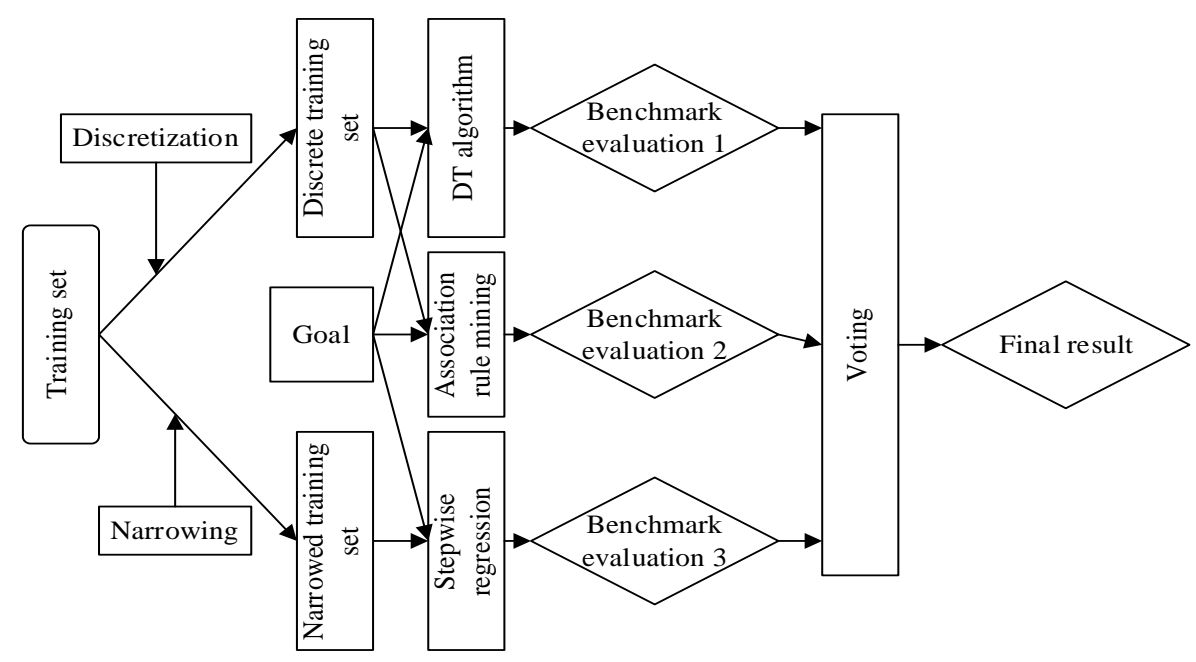

Fig. 2. Structure of the assessment model for the improvement of students' key competencies

\section{$5 \quad$ Experiments and results analysis}

After carrying out experiments on the improvement of students' key competencies, this paper tests students in 20 classes of 3 grades of an institution of higher learning in Beijing, China, based on their evaluation results on online and offline experiential teaching and itinerary assessment, in the light of expert comments and suggestions. The students are serious about the evaluation of each learning phase, which ensures the authenticity of the test results. The evaluation indices used in the test cover the three dimensions (theoretical concept, logical thinking, and inquiry ability) of students' key competencies. The purpose of the test is to judge whether the students experience changes in learning quality and key competencies through experiential teaching and itinerary assessment. For simplicity, the experiential teaching and itinerary assessment are collectively referred to as the practice.

Tables 1 and 2 present the analysis of the test results, and the results of independent samples t-test, respectively. Based on the test results before and after the practice, it is possible to evaluate the influence of experiential teaching and itinerary assessment on the improvement of students' key competencies reflected in the teaching of professional courses in colleges. The practice in the test case was assessed by the designed evaluation index system and evaluation flow. The results in Tables 1 and 2 show that the evaluation results after the practice were significantly higher than those before the practice, with a slight decline in the standard deviation. The evaluation results after the practice were relatively clustered, and varied slightly from student to student. The independent samples t-test on the evaluation results suggest that the pvalue of 0.001 was smaller than the significance level of 0.01 . Thus, there was a significance difference among the evaluation results. To sum up, experiential teaching 
Paper - Influence of Experiential Teaching and Itinerary Assessment on the Improvement of Key...

and itinerary assessment can significantly improve students' key competencies, and benefit individual development of the students.

Table 1. Analysis of test results

\begin{tabular}{|c|c|c|c|}
\hline \multirow{4}{*}{ Class statistics } & \multicolumn{3}{|c|}{ Evaluation result } \\
\cline { 2 - 4 } & Class & Post-practice & Pre-practice \\
\cline { 2 - 4 } & Number of students & 52 & 61 \\
\cline { 2 - 4 } & Mean & 62.1423 & 58.2635 \\
\cline { 2 - 4 } & Standard deviation & 13.82547 & 11.30458 \\
\cline { 2 - 4 } & Mean standard error & 1.52581 & 1.82548 \\
\hline
\end{tabular}

Table 2. Results of independent samples t-test

\begin{tabular}{|l|c|c|c|}
\hline \multicolumn{2}{|c|}{ Type of variance } & Equal variances assumed & Equal variances not assumed \\
\hline Mean difference & & 11.257 & 11.24 \\
\hline Standard error difference & & 2.354 & 2.675 \\
\hline F-score & & 0.625 & \\
\hline Significance & & 0.824 & 111.162 \\
\hline Degree of freedom & & 113 & 6.428 \\
\hline $\begin{array}{l}\text { 95\% confidence interval of the } \\
\text { difference }\end{array}$ & Upper & 16.254 & 16.248 \\
\cline { 2 - 4 } & Lower & 6.526 & 4.827 \\
\hline T-value & & 4.725 & 0.001 \\
\hline Significance & & 0.001 & \\
\hline
\end{tabular}

Table 3 compares the evaluation results of key competencies in different dimensions before and after the practice. In general, the evaluation results after the practice differed significantly from those before the practice: the former were higher than the latter. In the dimension of theoretical concept, the post-practice mean was 10.25 , higher than the pre-practice mean of 9.54. In the dimension of logical thinking, the post-practice mean was 16.31 , much higher than the pre-practice mean of 12.44 . In the dimension of inquiry ability, the post-practice mean was 9.23 , posing a sharp contrast with the pre-practice mean of 7.65. Of course, the itinerary assessment was evaluated for limited times, under the constraint of different teaching phases. The promoting effect on some dimensions was not that obvious. On the whole, experiential teaching and itinerary assessment can improve students' key competencies in any phase of student learning.

Table 3. Evaluation results of key competencies in different dimensions before and after the practice

\begin{tabular}{|l|c|c|c|}
\hline \multicolumn{1}{|c|}{ Dimension } & Theoretical concept & Logical thinking & Inquiry ability \\
\hline Index number & $E T_{211}, E T_{212}$ & $E T_{221}, E T_{222}$ & $E T_{231}, E T_{232}$ \\
\hline Post-practice mean & $10.25 / 16$ & $16.31 / 24$ & $9.23 / 19$ \\
\hline Pre-practice mean & $9.54 / 19$ & $12.44 / 25$ & $7.65 / 29$ \\
\hline
\end{tabular}


Next, the evaluation results on student participation in the entire teaching process were divided into different intervals. Three students were extracted from each interval after the practice. Then, the authors judged whether the actual learning quality and key competence improvement of these student are in line with the comprehensive evaluation results, which are obtained through full consideration of the opinions of self-evaluation, mutual evaluation, and teacher evaluation. To obtain the actual learning state, the authors read the students' self-evaluation and reflections on each course, and interviewed the head teacher and course teachers about the improvement of students' key competencies. Table 4 shows the consistency between the comprehensive evaluation results and the actual situation.

As shown in Table 4, the comprehensive evaluation results of our model were basically consistent with the actual situation obtained through the survey on selfevaluation, mutual evaluation, and teacher evaluation. The consistency was particularly high between the comprehensive evaluation results and teacher evaluation results. This means the improvement of students' key competencies through the practice is recognized by both teachers and students, and our model outputs fair, and reasonable evaluation results. Therefore, our model is an effective tool.

Table 4. Consistency between the comprehensive evaluation results and the actual situation

\begin{tabular}{|c|c|c|c|c|c|c|c|c|c|}
\hline Score interval & \multicolumn{3}{|c|}{$[55,70]$} & \multicolumn{3}{|c|}{$[70,85]$} & \multicolumn{3}{|c|}{$[85,100]$} \\
\hline Student ranking & 1 & 2 & 3 & 1 & 2 & 3 & 1 & 2 & 3 \\
\hline $\begin{array}{l}\text { Comprehensive } \\
\text { evaluation }\end{array}$ & 78 & 73 & 76 & 86 & 84 & 87 & 95 & 93 & 91 \\
\hline Self-evaluation & $\begin{array}{c}\text { Slightly } \\
\text { consistent }\end{array}$ & $\begin{array}{c}\text { Slightly } \\
\text { consistent }\end{array}$ & $\begin{array}{c}\text { Strongly } \\
\text { consistent }\end{array}$ & $\begin{array}{c}\text { Fully } \\
\text { consistent }\end{array}$ & $\begin{array}{l}\text { Fully } \\
\text { con- } \\
\text { sistent }\end{array}$ & $\begin{array}{l}\text { Fully } \\
\text { con- } \\
\text { sistent }\end{array}$ & $\begin{array}{c}\text { Slightly } \\
\text { con- } \\
\text { sistent }\end{array}$ & $\begin{array}{l}\text { Strong- } \\
\text { ly } \\
\text { con- } \\
\text { sistent }\end{array}$ & $\begin{array}{c}\text { Slightly } \\
\text { con- } \\
\text { sistent }\end{array}$ \\
\hline $\begin{array}{l}\text { Mutual evalua- } \\
\text { tion }\end{array}$ & $\begin{array}{c}\text { Fully } \\
\text { consistent }\end{array}$ & $\begin{array}{c}\text { Fully } \\
\text { consistent }\end{array}$ & $\begin{array}{c}\text { Fully } \\
\text { consistent }\end{array}$ & $\begin{array}{c}\text { Slightly } \\
\text { consistent }\end{array}$ & \begin{tabular}{|c|} 
Strongly \\
con- \\
sistent
\end{tabular} & $\begin{array}{c}\text { Strongly } \\
\text { con- } \\
\text { sistent }\end{array}$ & $\begin{array}{c}\text { Slightly } \\
\text { con- } \\
\text { sistent }\end{array}$ & $\begin{array}{l}\text { Con- } \\
\text { sistent }\end{array}$ & $\begin{array}{l}\text { Slightly } \\
\text { con- } \\
\text { sistent }\end{array}$ \\
\hline $\begin{array}{l}\text { Teacher eval- } \\
\text { uation }\end{array}$ & $\begin{array}{c}\text { Strongly } \\
\text { consistent }\end{array}$ & $\begin{array}{c}\text { Strongly } \\
\text { consistent }\end{array}$ & $\begin{array}{c}\text { Strongly } \\
\text { consistent }\end{array}$ & $\begin{array}{c}\text { Strongly } \\
\text { consistent }\end{array}$ & $\begin{array}{l}\text { Fully } \\
\text { con- } \\
\text { sistent }\end{array}$ & $\begin{array}{l}\text { Fully } \\
\text { con- } \\
\text { sistent }\end{array}$ & $\begin{array}{l}\text { Fully } \\
\text { con- } \\
\text { sistent }\end{array}$ & $\begin{array}{c}\text { Strong- } \\
\text { ly } \\
\text { con- } \\
\text { sistent }\end{array}$ & \begin{tabular}{|c|} 
Strong- \\
ly \\
con- \\
sistent
\end{tabular} \\
\hline
\end{tabular}

Figure 3 compares the evaluation effect of each benchmark evaluation model (stepwise regression, DT algorithm, and association rule mining) with that of the integrated model. The stepwise regression performed generally on sample sets 7 and 8 , DT algorithm worked poorly on sample sets 1,5 , and 6 , association rule mining did not work well on sample sets 4 and 7 , while our integrated model achieved the optimal effect on sample sets 1-8. Overall, the integrated model performed more stably than the three contrastive models. 


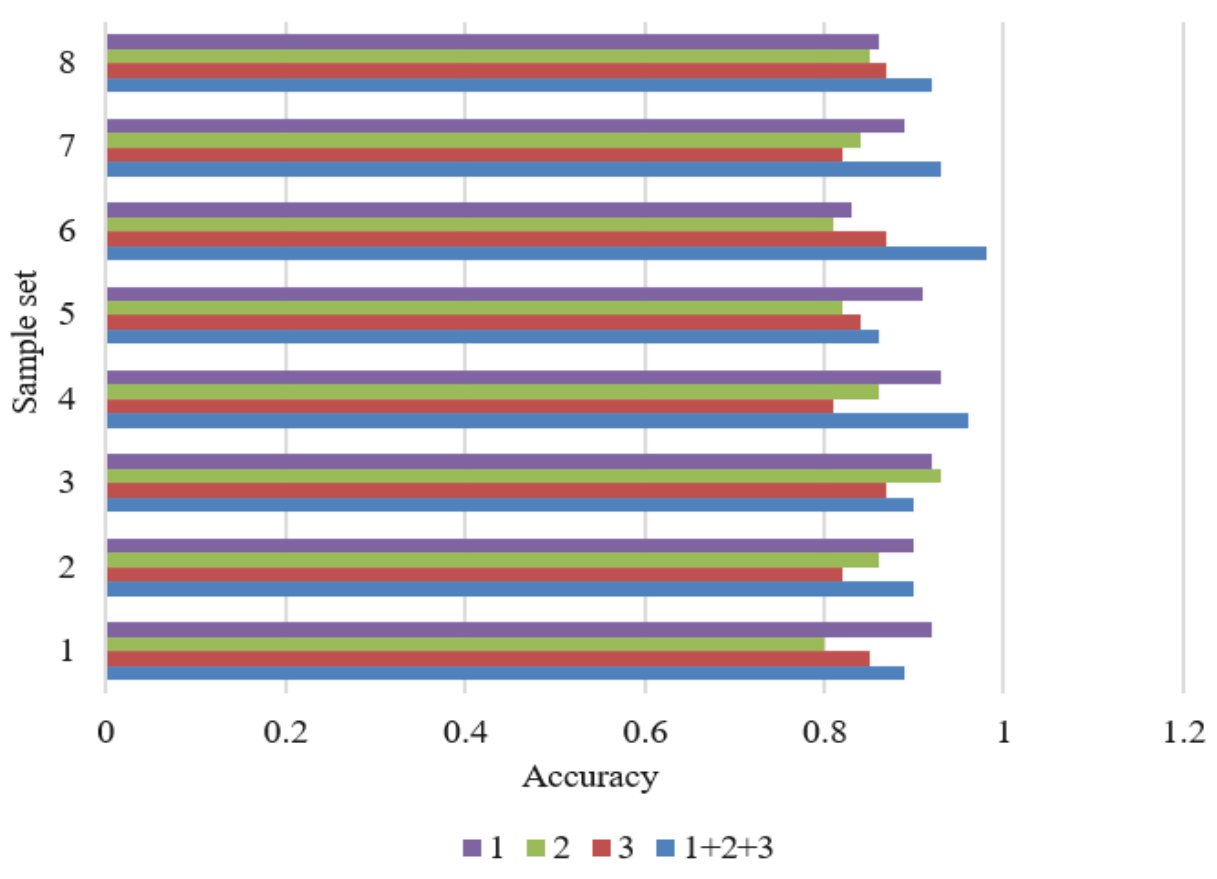

Fig. 3. Evaluation effect of benchmark evaluation models vs. evaluation effect of integrated model

Figure 4 provides the students' satisfaction with learning state before and after the practice. After implementing experiential teaching and itinerary assessment, most students were more satisfied with their learning state, as the satisfaction rose from $59.62 \%$ to $86.75 \%$. Hence, the students are content with the improvement of their key competences realized through the practice. That is, their learning quality and learning effect are both improving. 


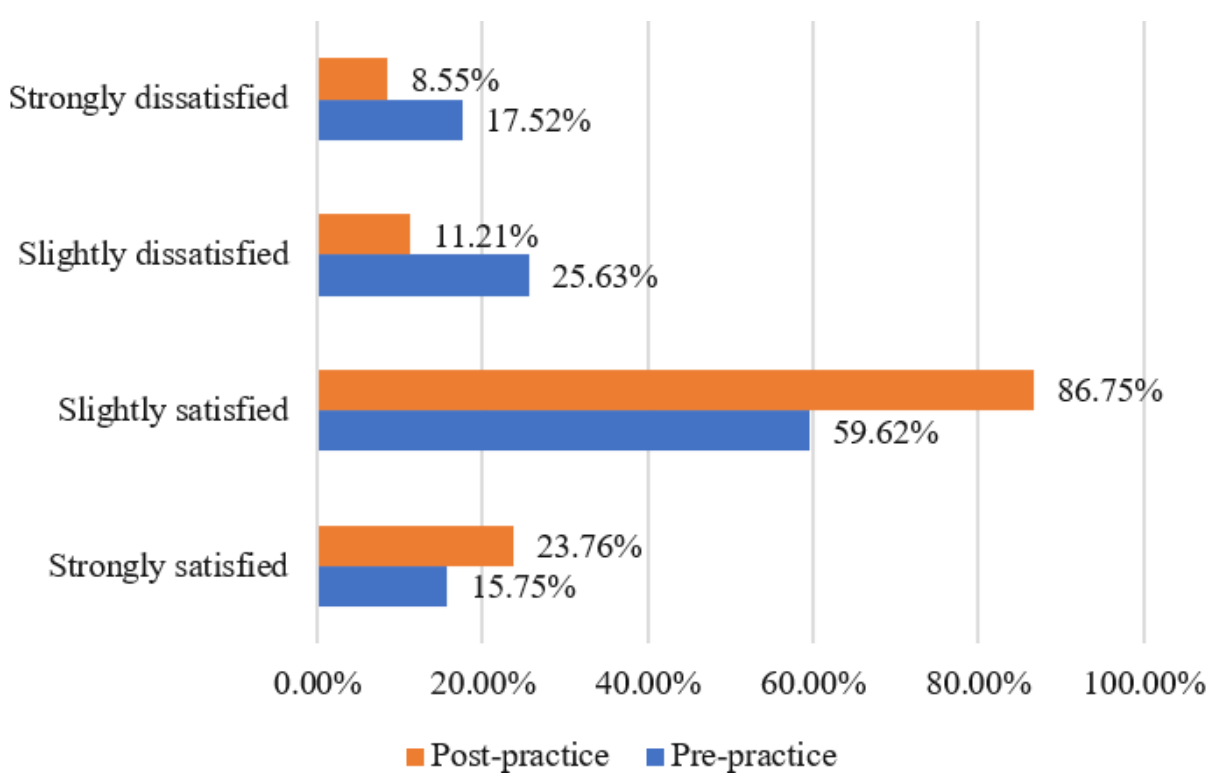

Fig. 4. Students' satisfaction with learning state before and after the practice

\section{Conclusions}

This paper evaluates the influence of experiential teaching and itinerary assessment on the improvement of students' key competencies. Specifically, stepwise regression, ID3 algorithm, and association rule mining technique were applied for the benchmark evaluation of the improvement of students' key competencies, and the three benchmark evaluation models were combined into an integrated model. On this basis, the evaluation results on the key competencies in different dimensions through the practice were summarized by test result analysis and independent samples t-test. The summary proves the significant promoting effect of experiential teaching and itinerary assessment on students' key competencies. Next, the authors judged whether the comprehensive evaluation results are consistent with the actual learning quality and key competence improvement of the students, and found that the results are highly consistent with teacher evaluation results. Hence, the proposed model can output fair and reasonable evaluation results. Finally, the effectiveness of the integrated model was demonstrated through a comparison against the three benchmark evaluation models.

\section{$7 \quad$ References}

[1] Li, Y.F. (2020). Visual Education of Music Course for College Students Based on HumanComputer Interaction, International Journal of Emerging Technologies in Learning, 15(2): 175-186. https://doi.org/10.3991/ijet.v15i02.12535 
Paper-Influence of Experiential Teaching and Itinerary Assessment on the Improvement of Key...

[2] Adanan, H., Adanan, M., Herawan, T. (2020). M-WebQuest Development: Reading Comprehension of Senior High School Students in Indonesia, International Journal of Emerging Technologies in Learning, 15(3): 74-92. https://doi.org/10.3991/ijet.v15i03.10628

[3] Ruan, Y.H., Dou, M., Liu, Y. (2013). The evaluation of international education college students' comprehensive quality. In Advanced Materials Research, 694: 3667-3670. https://doi.org/10.4028/www.scientific.net/AMR.694-697.3667

[4] Ali, Y., Mohamad, T.I., Shamsudeen, A. (2010). The impact on quality of students through participation in international challenge project-A case study on UKM's students. In 2010 2nd International Congress on Engineering Education, 79-82. https://doi.org/10.1109/ ICEED.2010.5940768

[5] McPherson, P., Reiter, K. (2019). Providing students with practical experience in quality control through industry partnerships. In 2019 CIEC. https://peer.asee.org/31495

[6] Spinellis, D. (2021). Why computing students should contribute to open source software projects. Communications of the ACM, 64(7): 36-38. https://doi.org/10.1145/3437254

[7] Chen, B., Hwang, G.H., Lin, T.S. (2020). Impacts of a dynamic grouping strategy on students' learning effectiveness and experience value in an item bank- based collaborative practice system. British Journal of Educational Technology, 51(1): 36-52. https://doi.org/ $\underline{10.1111 / b j e t .12794}$

[8] Li, S.S., Wu, X.J., Quan, C.B. (2017). Training students' practical and innovation ability in hardware experiment. In 2017 IEEE Frontiers in Education Conference (FIE), 1-5. https://doi.org/10.1109/FIE.2017.8190565

[9] Fukuzawa, R., Joho, H., Maeshiro, T. (2015). Practice and experience of task management of university students: Case of University of Tsukuba, Japan. Education for Information, 31(3): 109-124. https://doi.org/10.3233/EFI-150953

[10] Lee, Y.M., Cho, S. (2015). How college students experience work: implications for policy and practice development. International Journal of u-and e-Service, Science and Technology, 8(8): 285-296. https://doi.org/10.14257/ijunesst.2015.8.8.29

[11] Guo, W., Niu, Y. (2021). Interactive teaching system of basketball action in college sports based on online to offline mixed teaching mode. Mobile Information Systems, 2021. https://doi.org/10.1155/2021/9994050

[12] Tang, S.C. (2021). Application of computer in mixed teaching of higher mathematics. In 2021 International Conference on Internet, Education and Information Technology (IEIT), 525-528. https://doi.org/10.1109/IEIT53597.2021.00123

[13] Tan, B., Cheng, G., Yu, R., Cai, S. (2021). Online course construction and multidimensional mixed teaching: research and practice. In 2021 16th International Conference on Computer Science \& Education (ICCSE), 920-925. https://doi.org/10.1109/ICCSE 51940.2021.9569329

[14] Hui, Y. (2021). Evaluation of blended oral English teaching based on the mixed model of SPOC and deep learning. Scientific Programming, 2021. https://doi.org/10.1155/2021/ 7044779

[15] Cao, Z. (2021). Construction and exploration of mixed teaching mode in college physical education. In The Sixth International Conference on Information Management and Technology, 1-4. https://doi.org/10.1145/3465631.3465970

[16] Qyyum, M.A., Ahmed, F., Nawaz, A., He, T., Lee, M. (2021). Teaching-learning selfstudy approach for optimal retrofitting of dual mixed refrigerant LNG process: Energy and exergy perspective. Applied Energy, 298: 117187. https://doi.org/10.1016/j.apenergy. 2021.117187

[17] Yanfei, M. (2021). Online and offline mixed intelligent teaching assistant mode of English based on mobile information system. Mobile Information Systems, 2021. https://doi.org/ $\underline{10.1155 / 2021 / 7074629}$

[18] Santillan-Rosas, I., Yusta-García, R., Heredia-Escorza, Y. (2019, October). Experiential teaching for sustainable development. In Proceedings of the Seventh International Confer- 
Paper-Influence of Experiential Teaching and Itinerary Assessment on the Improvement of Key...

ence on Technological Ecosystems for Enhancing Multiculturality, 481-485. https://doi. org $/ 10.1145 / 3362789.3362883$

[19] Guerra, M., Shealy, T. (2018). Teaching user-centered design for more sustainable infrastructure through role-play and experiential learning. Journal of Professional Issues in Engineering Education and Practice, 144(4): 05018016. https://doi.org/10.1061/(asce)ei. 1943-5541.0000385

[20] Marriott, P., Lau, A. (2007). The impact of phased on-line summative assessment on students' learning on a first year undergraduate accounting module-a case study. ECEL2007Proceedings of the European Confernce on e-Learning 2007: ECEL2007, 427.

[21] Jiang, Y.H., Jiang, Y. (2021). Evaluation method of online learning process under the background of educational big data. In International Conference on E-Learning, EEducation, and Online Training, 403-414. https://doi.org/10.1007/978-3-030-84386-1_33

[22] Xia, Z.M., Wang, J.M., Yan, X. (2021). Research on construction and correlation analysis of whole process teaching quality evaluation system under the blended learning mode. In 2021 2nd International Conference on Education, Knowledge and Information Management (ICEKIM), 478-482. https://doi.org/10.1109/ICEKIM52309.2021.00111

[23] Maizeli, A., Nerita, S., Afza, A. (2020). An analysis of cognitive assessment readability toward biology learning outcome and process evaluation course. In Journal of Physics: Conference Series, 1521(4): 042014. https://doi.org/10.1088/1742-6596/1521/4/042014

\section{Authors}

Boru Lu, female, lecturer, was born in April 1988, with a master's degree. Research direction: ideological and political education of college students. Currently working in Yanching Institute of Technology, which is located in Sanhe City, Hebei Province, China. Engaged in the work of college counselors for 9 years. A total of 19 provincial honors, 2 municipal honors and 10 school honors have been won. Five papers were published by the first author and four by the second author in national academic journals. Presided over 1 student education management project of Langfang Science and Technology Bureau and participated in 2 provincial scientific research projects (Email: luboru@yit.edu.cn).

Fan Zheng, male, Manchu, lecturer, member of the Communist Party of China, senior professional instructor, advanced moral education worker in Hebei Province, was born in July 1983, in Jinzhou City, Liaoning Province, China. With a Bachelor's degree, majors in Arts in English from Liaoning Institute of Science and Technology in 2007. He has been engaged in student work for many years and is currently the general party branch secretary of the Engineering College of Yanching Institute of Technology. He has published many papers on party building in colleges and universities and ideological education of college students. More than 10 papers have been published in core journals, national and provincial periodicals, and have repeatedly won honorary titles such as "Advanced worker of moral Education in Hebei Province", "New long March Raider of Sanhe City", "excellent Party worker", "Outstanding Communist Party member", "excellent teacher", "Top Ten counselors", "Advanced individual in Employment" and so on.

Article submitted 2021-10-24. Resubmitted 2021-12-13. Final acceptance 2021-12-21. Final version published as submitted by the authors. 